\title{
Brain MRI findings in an infant with congenital biotinidase deficiency
}

\author{
Priya Singh 지 , Rohit Gurnani, Anil Rawat, Anit Parihar
}

Department of Radiodiagnosis, King George Medical College, Lucknow, Uttar Pradesh, India

\section{Correspondence to} Dr Priya Singh;

singhpriya2861990@gmail.com

Accepted 27 September 2021

Check for updates

(c) BMJ Publishing Group Limited 2021. No commercial re-use. See rights and permissions. Published by BMJ.

To cite: Singh P, Gurnani $R$, Rawat $\mathrm{A}$, et al. BMJ Case Rep 2021;14:e246167. doi:10.1136/bcr-2021246167

\section{DESCRIPTION}

A 5-month-old male child presented with reports of multiple episodes of seizures and ataxia since the neonatal period. Neurodevelopmental delay was present with poor neck holding and delayed milestones. He was born at term without any perinatal complications. Except for developmental delay, general examination of the child was completely normal. No similar reports were present in other siblings or family members. Routine blood investigations were completely normal. The clinical possibility of metabolic or developmental brain disorders was considered. For further evaluation, brain MRI was done. MRI at 1.5 Tesla revealed bilaterally symmetrical areas of diffusion restriction in the bilateral posterior limb of internal capsule, peritrigonal white matter along optic radiation, splenium of the corpus callosum, medial temporal gyri and cerebral peduncles on diffusion-weighted imaging (DWI) (figure 1). Involved areas also show subtle hyperintensity on T2-weighted and fluidattenuated inversion recovery sequence images (figure 2B, C). Associated diffuse brain atrophy was seen with bilateral subdural hygroma in frontal and temporal regions (figure 2A-C). Myelination was mildly delayed for age. Magnetic resonance spectroscopy (MRS) revealed elevated lactate and choline with reduced $\mathrm{N}$-acetyl aspartate (NAA) (figure 2D, E). Based on MRI findings, a diagnosis of congenital biotinidase deficiency (CBD) was made. Another close differential diagnosis was maple syrup urine disease, which has earlier and different clinical presentations and involves basal ganglia and thalami. Biochemical assay of blood confirmed the presence of biotinidase deficiency with low serum levels of $0.2 \mathrm{nmole} / \mathrm{min} / \mathrm{mL}$ (normal range 3.1 to $6.7 \mathrm{nmole} / \mathrm{min} / \mathrm{mL}$ ). Blood lactate and pyruvate levels were also elevated. The clinical phenotype of
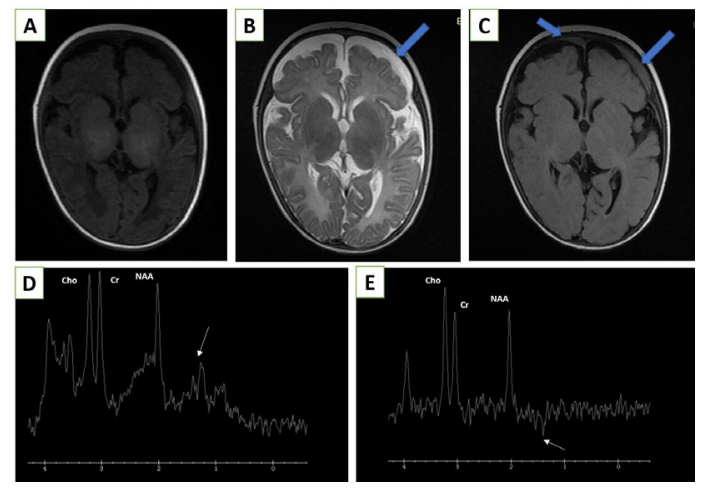

Figure 2 ( $A-C)$ MRI brain axial images at the level of Sylvain fissure. (A) T1-weighted image, (B) T2-weighted image and (C) fluid attenuated inversion recovery (FLAIR) image shows mild diffuse cerebral atrophy, bilateral subdural hygroma (blue arrows), delayed myelination and subtle T2/FLAIR hyperintensity along the posterior limb of the internal capsule and peritrigonal white matter. (D and E) Magnetic resonance spectroscopy at TE $35 \mathrm{~ms}$ and TE 144 ms, respectively, show mildly elevated choline, decreased $\mathrm{N}$-acetyl aspartate peak and elevated lactate (white arrows).

the child was partial. He was treated with supplementation of biotin ( $5 \mathrm{mg}$ per day orally), leading to gradual improvement of symptoms.

CBD is a rare autosomal recessive reversible metabolic encephalopathy. Biotin in an unbound state acts as a cofactor or coenzyme for carboxylase enzyme required to synthesise fatty acid, amino acid metabolism and gluconeogenesis. Deficiency of biotinidase hampers cleavage of biotin from biocytin, making it unavailable for carboxylase enzyme resulting in energy depletion and anaerobic metabolism. ${ }^{1}$ Clinical features of CBD include
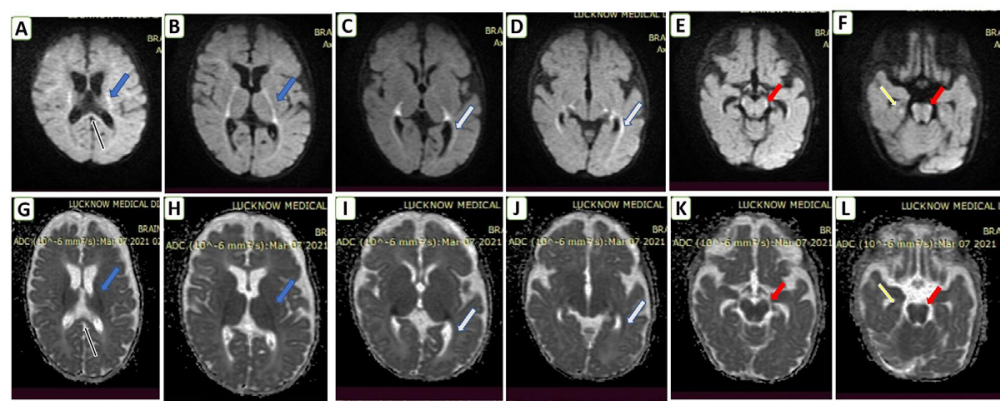

Figure 1 MRI brain axial images from cranial to caudal. (A-F) Diffusion-weighted sequence images and (G-L) corresponding apparent diffusion coefficient (ADC) images show bilaterally symmetrical areas of diffusion restriction in splenium of corpus callosum (black arrows), posterior limb of internal capsule (blue arrows), peritrigonal white matter along optic radiation (white arrows), cerebral peduncles (red arrows) and medial temporal gyri (yellow arrows). 
seizures, hypotonia, ataxia, developmental delay, sensorineural hearing loss, visual impairment, alopecia, skin pigmentation and dermatitis. Biotin therapy, if initiated in early infancy, can produce a complete reversal of clinical and radiological findings. ${ }^{1}$

Knowledge of neuroimaging in CBD is limited to few previous case reports. The most common MRI abnormality reported in the literature is cerebral atrophy which is sometimes associated

\section{Patient's perspective}

Patient's mother-My child was having repeated abnormal movements and seizures since birth. He was also lagging in overall development as compared with another child of the same age group. I have consulted to doctor who ordered a brain MRI. Doctors at MRI identified some abnormality in his brain and talked to my doctor, and finally, they ordered some blood tests. Although the blood report confirmed some congenital abnormality, doctors assured me that it is treatable with simple medications. I was delighted to know this. Now, after 3 months of treatment, my child is fine and doing well. I am very grateful to all the doctors involved in the treatment of my child.

\section{Learning points}

- Congenital biotinidase deficiency is a rare autosomal recessive metabolic encephalopathy that can be cured completely if biotin therapy is started in the early stage of the disease.

- Knowledge of characteristic brain MRI, diffusion-weighted imaging and magnetic resonance spectroscopy (MRS abnormalities could help diagnose this congenital metabolic encephalopathy.

- Diffuse brain atrophy, delayed myelination, diffusion restriction along corticospinal tracts and elevated lactate on MRS are the unique feature of this disease on MRI. with subdural hygromas or haematoma. ${ }^{2}$ Delayed myelination and white matter oedema are also common imaging findings. ${ }^{2}$ However, these findings reflect the late stage of the disease. DWI abnormalities have been described previously in four patients showing symmetrical diffusion restriction in variable areas like bilateral perirolandic white matter, corona radiata, posterior limb of the internal capsule, hippocampus, optic tract, brainstem, middle cerebellar peduncle, parieto-occipital grey matter and splenium of the corpus callosum. ${ }^{2-5}$ MRS characteristically shows lactate peak, low NAA and reversal of choline to creatine ratio, which is consistent with the underlying pathophysiology. ${ }^{2}$ In our case, both acute and chronic abnormalities were present. Thus, knowledge of varied MRI features of CBD can help in prompt diagnosis of potentially treatable and reversible metabolic encephalopathy.

Contributors Data was compiled and the report was written by PS. RG helped in the inception of the report, image collection and final review. The manuscript revision and the final correction were done by AR and AP.

Funding The authors have not declared a specific grant for this research from any funding agency in the public, commercial or not-for-profit sectors.

Competing interests None declared.

Patient consent for publication Consent obtained from parent(s)/guardian(s).

Provenance and peer review Not commissioned; externally peer reviewed.

\section{ORCID iD}

Priya Singh http://orcid.org/0000-0003-0110-4242

\section{REFERENCES}

1 Gulati S, Passi GR, Kumar A, et al. Biotinidase deficiency--a treatable entity. Indian J Pediatr 2000;67:464-6.

2 Desai S, Ganesan K, Hegde A. Biotinidase deficiency: a reversible metabolic encephalopathy. neuroimaging and MR spectroscopic findings in a series of four patients. Pediatr Radiol 2008:38:848-56.

3 Ranjan RS, Taneja S, Singh A, et al. Congenital biotinidase deficiency - MRI findings in two cases. Indian J Radiol Imaging 2019;29:99-103.

4 Soares-Fernandes JP, Magalhães Z, Rocha JF, et al. Brain diffusion-weighted and diffusion tensor imaging findings in an infant with biotinidase deficiency. AJNR Am J Neuroradiol 2009;30:E128

5 Bhat MD, Bindu PS, Christopher R, et al. Novel imaging findings in two cases of biotinidase deficiency-a treatable metabolic disorder. Metab Brain Dis 2015:30:1291-4.

Copyright 2021 BMJ Publishing Group. All rights reserved. For permission to reuse any of this content visit https://www.bmi.com/company/products-services/rights-and-licensing/permissions/

BMJ Case Report Fellows may re-use this article for personal use and teaching without any further permission.

Become a Fellow of BMJ Case Reports today and you can:

- Submit as many cases as you like

- Enjoy fast sympathetic peer review and rapid publication of accepted articles

- Access all the published articles

Re-use any of the published material for personal use and teaching without further permission

Customer Service

If you have any further queries about your subscription, please contact our customer services team on +44 (0) 2071111105 or via email at support@bmj.com.

Visit casereports.bmj.com for more articles like this and to become a Fellow 